\title{
PREDIKSI DATA ARUS LALU LINTAS DI KABUPATEN JEPARA MENGGUNAKAN ALGORITMA NEURAL NETWORK
}

\author{
Teguh Tamrin \\ Program Studi Teknik Informatika, Fakultas Sains dan Teknologi, Universitas Islam Nahdlatul \\ Ulama Jepara \\ Jl. Taman Siswa (Pekeng) Tahunan Jepara 59427 \\ E-Mail :teguh@unisu.ac.id
}

\begin{abstract}
The imbalance in the growth of transportation facilities especially motorcycles and private vehicles is growing very rapidly from the growth of transportation infrastructure when it occurs in traffic jams. Jepara regency is included in 35 districts / cities in the Province of Central Java.

Some of the factors that affect congestion in Jepara are: 1) Some schools in Jepara are located on the roadside, creating congestion due to compilation. Morning hours leave for school in the morning and afternoon come home to pick up school and find people who sell in front of school. Number of Industries that stand in Jepara while the capacity of the road is narrow. 3) Parking liars I haphazard. Therefore, this study was conducted to prove the most accurate neural networks in traffic prediction data by using data of Jepara district traffic volume.

The research method used is experimental method with testing algorithm to determine the price in data processing. In this study using a dataset of 70 records with 50 data sharing training and 20 data testing. Other parameters: Name (ID), Time, Motor Cycle (MC), Light Vehicle (LV), Heavy Vehicle (HV), Volume (C), Volume (V), V/C and conclusion. The outcomes in question are scientific journals and technological readiness levels (TKT), including into TKT level 3.
\end{abstract}

Keywords : Prediction, traffic flow, neural network, algorithm

\section{ABSTRAK}

Ketidak seimbangan pertumbuhan sarana transportasi khususnya sepeda motor dan kendaraan pribadi berkembang sangat pesat daripada pertumbuhan prasarana transportasi sehingga berdampak pada kemacetan lalu lintas. Kabupaten Jepara termasuk ke dalam 35 kabupaten/kota yang ada di Propinsi Jawa Tengah.

Beberapa faktor yang mempengaruhi kemacetan di Jepara adalah :1) Beberapa sekolah yang ada di Jepara terletak di pinggir jalan sehingga menimbulkan kemacetan karena ketika pagi jam berangkat sekolah parkir pengantar dan siang jam pulang sekolah ketika menjemput dan banyaknya orang yang berjualan di depan sekolah.2) Banyaknya Industri yang berdiri di Jepara sedangkan kapasitas jalan sempit. 3) Parkir liar/sembarangan. Oleh sebab itu, penelitian ini dilakukan untuk membuktikan algoritma neural network adalah algoritma yang paling akurat dalam memprediksi jumlah arus lalu lintas di kabupaten Jepara.

Metode penelitian yang digunakan adalah penelitian eksperimen dengan pengujian algoritma untuk menentukan akurasi dalam pengolahan data. Pada penelitian ini menggunakan dataset sejumlah 70 record dengan pembagian 50 data training dan 20 data testing. Parameter yang digunakan antara lain : Nama (ID), Waktu, Motor Cycle (MC), Light Vehicle(LV), Heavy Vehicle (HV), Kapasitas (C), Volume (V), V/C dan kesimpulan label. Luaran yang dicapai adalah jurnal ilmiah dan tingkat kesiapan teknologi (TKT) termasuk ke dalam TKT tingkat 3.

Kata Kunci: Prediksi, arus lalu lintas, neural network, algoritma. 


\section{Pendahuluan}

Kabupaten Jepara termasuk ke dalam 35 kabupaten/kota yang ada di Propinsi Jawa Tengah, secara astronomis terletak antara $5^{\circ} 43^{\prime} 20,67^{\prime \prime}$ - 6०47'25,83" LS dan $110^{\circ} 9^{\prime} 48,02^{\prime \prime}$ - 110 $58^{\prime} 37,40^{\prime \prime}$ BT . Batas wilayah kabupaten Jepara di sebelah barat dan utara dibatasi oleh laut Jawa sedangkan sebelah timur berbatasan dengan Kabupaten Kudus dan Pati dan sebelah selatan berbatasan dengan Kabupaten Demak. Menurut Badan Pusat Statistik jumlah penduduk Jepara pada tahun 2014 sekitar 1,170,797 jiwa. Pada cakupan yang lebih luas di seluruh Indonesia pada tahun 2011 panjang jalan nasional adalah $38.570 \mathrm{~km}$, jalan provinsi 48.020 $\mathrm{km}$ dan jalan kabupaten/kota 389.747 $\mathrm{km}$. Sedangkan panjang jalan di kabupaten Jepara adalah 789.703 km dan jalan kabupaten memiliki panjang 76,84 km. Pada tahun 2013, Data Kementrian Pekerjaan Umum (PU) menyatakan bahwa pertumbuhan jalan nasional pada tahun 2011 - 2012 adalah $2.5 \%$. Hal ini menunjukkan jumlah kendaraan semakin pesat. Salah satu faktor yang mempengaruhi transportasi adalah laju pertumbuhan daerah masing-masing.[1]

Loreno (2014) juga melakukan penelitian data arus lalu lintas yang menganalisa dan membandingkan data arus lalu lintas dengan menggunakan algoritma Back propagation - Neural Network (BP-NN), Adaptip Neuro Fuzzy Inference System (ANFIS), Wavelet Neural Network (WNN), dan Evolving Neural Network (ENN) pengukuran dikerja dilakukan dengan menghitung rata - rata error yang terjadi melalui besaran Root Mean Square Error (RMSE), Mean Absolute Percentase Error (MAPE), dan Mean Absolute Deviation (MAD) dan dihasilkan algoritma ENN lebih akurat.[3]

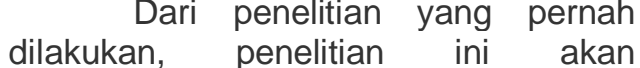
memprediksi data arus lalu lintas dengan menggunakan algoritma Neural Network dengan menggunakan data arus lalu lintas dari dinas perhubungan, komunikasi dan informasi kabupaten Jepara.

\section{Tinjauan Pustaka \\ Data Mining}

Data mining biasa disebut knowledge discovery in database (KDD), yaitu suatu kegiatan meliputi pengumpulan data, pemakaian data historis untuk menemukan keteraturan, pola atau hubungan dalam data set berukuran besar (Santoso,2007). Keluarannya bisa dipakai untuk memperbaiki pengambilan keputusan yang akan datang berdasarkan suatu informasi yang diperoleh dari historis. Data yang ada bisa berupa data pasien, mahasiswa, pemohon kredit,gambar atau pengukuran lain yang perlu diklasifikasikan atau relasi atributnya.

Data mining erat kaitannya dengan machine learning. Machine learning adalah suatu area dalam artificialintelligence atau kecerdasan buatan yang berhubungan dengan pengembangan teknik-teknik yang bisa diprogramkan dan belajar dari data masa lalu (Santoso,2007). Machine learning menjadi alat analisis dalam data mining. Gambar 2.1 merupakan pengelompokan data mining(Larose,2005). Kasus klasifikasi yang bersifat linear maupun non linear menjadi kajian yang menarik. Banyak metode yang dikembangkan untuk kelinearan data. Metode yang demikian tentu akan mempunyai performansi yang sesuai dengan kasusnya linear atau non linear. [5]

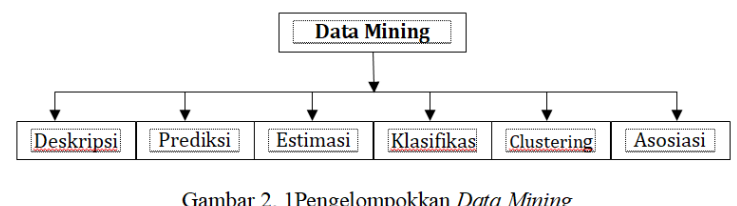

\section{Neural Network}

Artificial Neural Network (ANN) adalah model penalaran yang didasarkan pada jaringan saraf otak manusia. ANN terdiri dari prosesor dan saling berhubungan dan bersinergi yang disebut neuron. Neuron terhubung dengan pembobotan (weight) melewati sinyal neuron satu(1) ke neuron lainnya.

Artificial Neural Network bisa mengenal sinyal input yang berbeda dari 
yang sudah pernah diterima sebelumnya dan bisa bekerja meskipun beberapa neuron tidak bisa bekerja dengan sempurna. Bila satu neuron rusak maka neuron yang lain bisa dilatih untuk menggantikan fungsi neuron yang telah rusak. Model neuron ANN terdiri dari ; 1.summing function atau biasa di sebut dengan fungsi penjumlah, 2.activation function atau biasa disebut dengan fungsi aktivasi.3 keluaran (output).

Cara kerja Artificial Neural Network adalah input atau informasi dikirim ke neuron dengan bobot tertentu, diproses oleh suatu fungsi yang akan

menjumlahkan nilai-nilai bobot yang sudah ada. Hasil dari penjumlahan tersebut akan dibandingkan dengan threshold atau nilai ambang tertentu melalui fungsi aktivasi tiap-tiap neuron. Jika ada input melewati suatu nilai ambang tertentu, neuron akan aktif, jika tidak, neuron tidak diaktifkan. Neuron aktif akan mengirim output melalui bobot outputnya ke neuron yang terhubung.

Struktur Artificial Neural Network

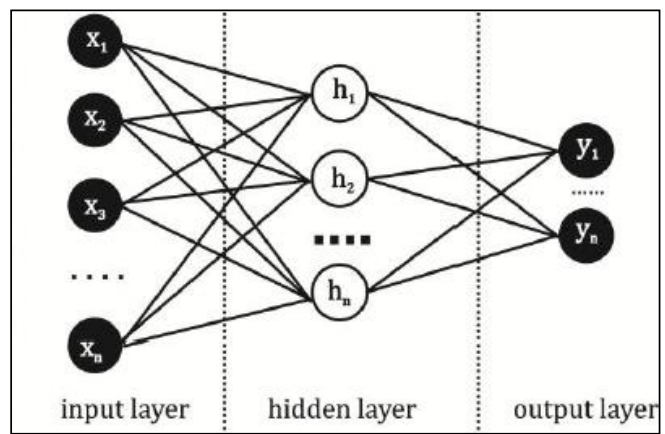

Gambar 2.2 Struktur Artificial Neural

Network

input layer $(x 1, x 2, x 3, \ldots, x n)$, terdiri dari unit-unit input. Unit-unit input menerima pola inputan data dari luar yang menggambarkan suatu permasalahan. Hidden Layer $(h 1, h 2, . ., h n)$, terdiri dari unit-unit tersembunyi. outputnya tidak bisa secara langsung dilihat. Sedang Output Layer $(y 1, \ldots, y n)$ terdiri dari unit-unit output yang menjadikan solusi ANN terhadap permasalahan.[6]

\section{Lalu lintas}

Karakteristik Arus Lalu Lintas

a) Karakteristik Primer
1) Volume

Volume adalah jumlah kendaraan yang lewat melalui satu(1) titik tetap pada jalan dalam satuan waktu. Volume dihitung kendaraan perhari atau kendaraan perjam. Volume dapat dinyatakan dalam suatu periode waktu yang lain.

2) Kecepatan

Kecepatan adalah suatu perubahan jarak dibagi dengan waktu. Kecepatan dapat diukur sebagai kecepatan (titik, perjalanan, ruang dan gerak). Kelambatan adalah waktu yang hilang pada saat berhentinya kendaraan, atau tidak sesuai dengan kecepatan yang diinginkan atau terjadi kemacetan lalu lintas.

3) Kepadatan

Kepadatan adalah jumlah kendaraan persatuan panjang jalan.

$$
K=\frac{N}{L}
$$

Keterangan:

$$
\begin{gathered}
\mathrm{K} \quad=\underset{(\text { kendaraan } / \mathrm{km})}{\text { kepadatan lalu lintas }} \\
\mathrm{N}=\underset{\text { jumlah kendaraan pada lintasan } 1}{\text { (kendaraan) }} \\
\mathrm{L}=\text { panjang lintasan }(\mathrm{km}) \\
\text { b) Karakteristik Sekunder }
\end{gathered}
$$

Hal yang paling penting adalah jarakantara, Ada dua parameter yaitu:

1) Waktu - antara kendaraan adalah waktu diperlukan antara satu(1) kendaraan dengan kendaraan lainya melalui satu titik tertentu yang tetap.

\begin{tabular}{|c|c|}
\hline Jarak-an & $\begin{array}{l}\text { tara kendaraan }= \\
\frac{1}{\text { kepadatan }}\end{array}$ \\
\hline $\begin{array}{l}\text { Besarnya } \\
\text { menentukan }\end{array}$ & $\begin{array}{l}\text { jarak-antara dapat } \\
\text { seorang pengemudi }\end{array}$ \\
\hline
\end{tabular}

waktu antara kendaraan rata

$$
- \text { rata }=\frac{1}{\text { volume }}
$$

2) Jarak - antara kendaraan yaitu jarak antara bagian depan satu kendaraan dengan bagian depan kendaraan berikutnya. 
harus mengerem dan kapan pengemudi mempercepat kendaraan. Jarak-antara dimana kendaraan yang berada didepan memperngaruhi pengemudi yang dibelakangnya disebut jarak-antara yang mengganggu. Hasil studi yang pernah dilakukan oleh Dinas Perhubungan, Komunikasi dan Informasi pada tahun 2015 menunjukkan bahwa besar nilai jarak-antara yang mengganggu berkisar antara $6-9$ detik.

c) Karakteristik Volume Lalu Lintas

Volume kepadatan lalu lintas suatu jalan bervariasi tergantung pada volume total dua(2) arah, arah lalu lintas, volume (harian, bulanan serta tahunan ) pada komposisi kendaraan yang bergerak lambat akan menjadi persoalan. Kendaraan besar, seperti bis dan truk dll memerlukan :

$\checkmark$ Jalan yang lebar, yaitu agar kendaraan lawan arah dapat berpapasan.

$\checkmark$ Jari-jari kelengkungan di tikungan yang lebih besar dan pelebaran di tikungan

$\checkmark$ Kebebasan vertikal yang lebih besar Untuk mendesai jalan dengan kapasitas yang memadai, terlebih dahulu harus menganalisa volume lalu lintas yang ada (eksisting), meliputi:

$\checkmark$ Variasi harian

$\checkmark$ Variasi jam

$\checkmark$ Variasi Bulanan

$\checkmark$ Variasi arah

$\checkmark$ Distribusi jalur

Arus lalu lintas harus dianalisis menurut standar tertentu sehingga dapat dibandingkan dari tahun ke tahun. Di perkotaan, volume arus lalu lintas puncak per jam digunakan untuk keperluan desain, karena volume ini jauh lebih besar dari volume pada waktu lainnya dalam sehari, pada saat itu variasi lalu lintas dalam satu (1) jam cenderung jauh lebih kecil dan variasi menurut arah biasanya tidak terlalu besar. Oleh karena itu, untuk jauh lebih kecil dan variasi menurut arah biasanya tidak terlalu besar. Istilah yang sering digunakan adalah :
- Lalu lintas Harian Rata-rata Tahunan atau biasa disingkat LHRT adalah total volume lalu lintas pada suatu jalan selama setahun dibagi 365.

- Volume Jam Perencanaan atau biasa disingkat (VJP atau DHV) adalah volume lalu lintas perjam yang digunakan untuk mendesain jalan.

- Lalu lintas Harian Rata-rata atau biasa disingkat dengan (LHR atau ADT) adalah volume lalu lintas suatu jalan selama periode tertentu, dianggap mewakili lalu lintas dalam setahun dibagi jumlah hari (365) pada periode tersebut.

- Lalu lintas Harian Rata-rata Bulanan adalah volume lalu lintas total selama sebulan tertentu, dibagi dengan jumlah hari dalam bulan tersebut.

- Volume Jam Maksimum Tahunan adalah volume per jam tertinggi selama satu tahun.

\section{Klasifikasi Kendaraan}

Jenis Kendaraan adalah faktor penting di dalam mendesain jalan. Pencacahan terklasifikasi di bedakan sampai 20 kelas kendaraan. Kategori kelas kendaraan:

1) Besar Kendaraan

2) Dimensi kendaraan untuk menentukan lebar jalur dan radius belokan

3) Karakteristik kecepatan kendaraan,pecepatan dan pengereman untuk menentukan kapasitas jalan Pembagiannya berdasar atas : kendaraan tidak bermotor, bermotor kecil, sedang dan besar.

4) Penggunaan kendaraan. Penklasifikasiannya adalah angkutan pribadi, angkutan umum, dan angkutan barang.

5) satuan dalam perencanaan lalu lintas yang disebut Satuan Mobil Penumpang (SMP). Menurut Dishub Kab. Jepara (2015) Besarnya Satuan Mobil Penumpang (SMP) yang direkomendasikan dalam IHCM adalah sebagai berikut: 
Tabel 2.1 Faktor Satuan Mobil Penumpang

\begin{tabular}{|c|c|c|c|c|}
\hline \multirow{2}{*}{ No } & \multirow{2}{*}{ Jenis Kendaraan } & \multirow{2}{*}{ Kelas } & \multicolumn{2}{|c|}{ SMP } \\
\hline & & & Ruas & Simpang \\
\hline \multirow[t]{4}{*}{1} & Sedan/jeep & LV & 1,00 & 1,00 \\
\hline & Opelet & & & \\
\hline & Mikrobus & & & \\
\hline & Pick Up & & & \\
\hline \multirow[t]{3}{*}{2} & Bus standar & $\mathrm{HV}$ & 1,20 & 1,30 \\
\hline & Truk Sedang & & & \\
\hline & Truk Berat & & & \\
\hline 3 & Sepeda Motor & MC & 0,25 & 0,40 \\
\hline \multirow[t]{3}{*}{4} & Becak & MC & 0,80 & 1,00 \\
\hline & Sepeda & & & \\
\hline & Andong,d11 & & & \\
\hline
\end{tabular}

Untuk mengukur kualitas pelayanan dari jaringan jalan adalah dengan menggunakan tingkat pelayanan, dimana parameter kualitas ruas jalan tersebut anatar lain adalah:
a) Kecepatan
b) Rasio V/C
c) Tingkat pelayanan

Untuk menentukan kualitas jalan tersebut

dapat dijelaskan pada tabel berikurt:

Tabel 2.2 Tingkat Pelayanan Jalan

\begin{tabular}{|c|c|c|}
\hline $\begin{array}{l}\text { Tingkat } \\
\text { Pelaya } \\
\text { nan }\end{array}$ & Karakteristik & $\begin{array}{l}\text { Batas } \\
\text { Lingku } \\
\mathrm{p} \text { V/C }\end{array}$ \\
\hline$A$ & $\begin{array}{lr}\text { Arus lalu } & \text { lintas } \\
\text { bebas } & \text { dengan } \\
\text { kecepatan } & \text { tinggi } \\
\text { pengemudi } & \text { bisa } \\
\text { memilih } & \text { kecepatan } \\
\text { maximal } & \text { sesuai } \\
\text { keinginan } & \\
\end{array}$ & $\begin{array}{l}0,00 \\
0,20\end{array}$ \\
\hline$B$ & 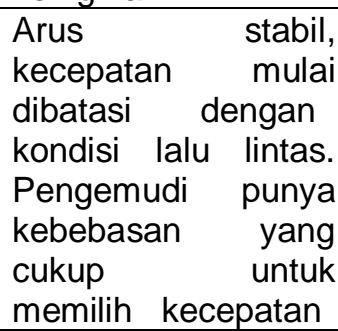 & $\begin{array}{l}0,20 \\
0,44\end{array}$ \\
\hline C & $\begin{array}{l}\text { Arus stabil, tetapi } \\
\text { kecepatan } \\
\text { pengemudi dibatasi } \\
\text { dalam memilih } \\
\text { kecepatan }\end{array}$ & $\begin{array}{l}0,45 \\
0,74\end{array}$ \\
\hline D & $\begin{array}{lr}\text { Arus } & \text { mendekati } \\
\text { tidak } & \text { stabil, } \\
\text { kecepatan } & \text { masih }\end{array}$ & $\begin{array}{l}0,75 \\
0,84\end{array}$ \\
\hline
\end{tabular}

\begin{tabular}{|c|c|c|}
\hline & $\begin{array}{l}\text { dikendalikan } \quad \mathrm{V} / \mathrm{C} \\
\text { masih dapat } \\
\text { ditolerir }\end{array}$ & \\
\hline$E$ & $\begin{array}{lr}\text { Volume lalu } & \text { lintas } \\
\text { mendekati } & \text { atau } \\
\text { berada } & \text { pada } \\
\text { kapasitas } & \text { arus } \\
\text { tidak } & \text { stabil } \\
\text { kecepatan } & \\
\text { terkadang } & \text { terhenti }\end{array}$ & $\begin{array}{l}0,85 \\
1,00\end{array}$ \\
\hline $\mathrm{F}$ & $\begin{array}{lr}\text { Arus } & \text { yang } \\
\text { dipaksakan } & \text { atau } \\
\text { macet, } & \text { kecepatan } \\
\text { rendah, } & \text { volume } \\
\text { dibawah } & \text { kapasitas. } \\
\text { Terjadi } & \text { antrian } \\
\text { panjang } & \text { dan } \\
\text { hambatan } & \text { yang } \\
\text { besar } & \end{array}$ & $>1$ \\
\hline
\end{tabular}

Tabel 2.3 Tingkat Pelayanan Persimpangan Bersinyal

\begin{tabular}{|l|l|}
\hline $\begin{array}{l}\text { Tingkat } \\
\text { Pelayanan }\end{array}$ & $\begin{array}{l}\text { Tundaan } \\
\text { (detik/kendaraan) }\end{array}$ \\
\hline A & $<5,0$ \\
\hline B & $5,10-15.0$ \\
\hline C & $15.1-25.0$ \\
\hline D & $25.1-40.0$ \\
\hline E & $40.1-60,0$ \\
\hline F & $>60$ \\
\hline
\end{tabular}

Tabel 2.4 Tingkat Pelayanan Persimpangan Prioritas

\begin{tabular}{|l|l|}
\hline $\begin{array}{l}\text { Tingkat } \\
\text { Pelayana } \\
n\end{array}$ & $\begin{array}{l}\text { Tundaan } \\
\text { (detik/kendaraan } \\
\text { ) }\end{array}$ \\
\hline A & $<5$ \\
\hline B & $5-10$ \\
\hline C & $11-20$ \\
\hline D & $21-30$ \\
\hline E & $31-45$ \\
\hline F & $>45$ \\
\hline
\end{tabular}

\section{Metode Penelitian}

Tahapan-tahapan Penelitian

Dalam penelitian ini, ada beberapa tahapan penelitian yang dilakukan, yaitu pengumpulan data dan 
pengolahan awal data, metode yang diusulkan, eksperimen dan pengujian model atau metode, Evaluasi dan validasi hasil.

tahapan penelitian seperti gambar 3.1.

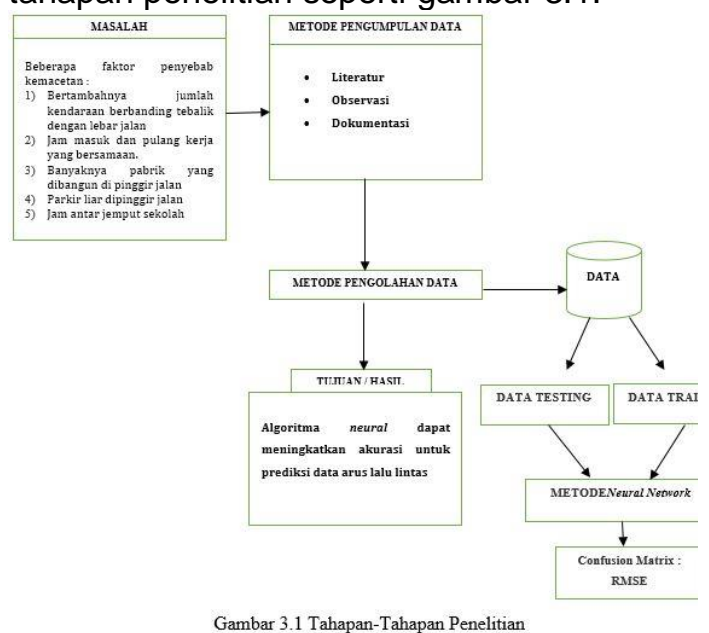

Pengumpulan Data

Pengumpulan data dalam penelitian ini meliputi :

a) Studi literatur yang digunakan sebagai referensi dalam penelitian bisa berupa buku, jurnal dan karya ilmiah yang relevan dengan algoritma klasifikasi data mining untuk prediksi data arus lalu lintas jangka pendek.

b) Dokumentasi dilakukan untuk meminta data yang ada di Dinas Perhubungan, Komunikasi dan Informasi Kabupaten Jepara. Dan dari hasil dokumentasi didapat data berupa laporan volume lalu lintas tahun 2014 dan 2015 yang akan dijadikan sebagai data testing dan data training dalam pengolahan data di aplikasi Rapid Miner.

B. Pengolahan Awal Data

Data yang didapat berupa laporan volume lalu lintas tahun 2014 sejumlah 40 records dan data tahun 2015 sejumlah 30 records. Dari records yang didapat yang digunakan 50 untuk data training dan 20 sebagai data testing. Parameter yang digunakan meliputi: Nama (ID), Waktu, Motor Cycle (MC), Light Vehicle(LV), Heavy Vehicle (HV), Kapasitas (C), Volume (V), Rasio V/C dan kesimpulan label.
Tabel 3.2 Faktor Satuan Mobil Penumpang

\begin{tabular}{|c|c|c|c|c|}
\hline \multirow[t]{2}{*}{ No } & \multirow{2}{*}{ Jenis Kendaraan } & \multirow[t]{2}{*}{ Kelas } & \multicolumn{2}{|c|}{$\begin{array}{l}\text { SMP (Satuan Mobil } \\
\text { Penumpang) }\end{array}$} \\
\hline & & & Ruas & Simpang \\
\hline 1 & $\begin{array}{l}\text { Sedan/jeep } \\
\text { Opelet } \\
\text { Mikrobus } \\
\text { Pick Up }\end{array}$ & LV & 1,00 & 1,00 \\
\hline 2 & $\begin{array}{l}\text { Bus standar } \\
\text { Truk Sedang } \\
\text { Truk Berat }\end{array}$ & $\mathrm{HV}$ & 1,20 & 1,30 \\
\hline $\begin{array}{l}3 \\
4\end{array}$ & $\begin{array}{l}\text { Sepeda Motor } \\
\text { Becak } \\
\text { Sepeda } \\
\text { Andong,dll }\end{array}$ & $\begin{array}{l}\text { MC } \\
\text { MC }\end{array}$ & $\begin{array}{l}0,25 \\
0,80\end{array}$ & $\begin{array}{l}0,40 \\
1,00\end{array}$ \\
\hline
\end{tabular}

Eksperimen dan Pengujian Metode

Setelah tahapan pengumpulan data dan pengolahan awal data kemudian tahapan dalam penelitian selanjutnya adalah eskperimen dan pengujian model/metode. Data yang diperoleh setelah pengolahan awal data kemudian dilakukan pengujian metode dengan data tersebut menggunakan tools rapid miner. Data akan diolah dengan menggunakan algoritma neural network dan akan dicari tingkat errornya atau Root Mean Square Error (RMSE).

Penelitian ini akan menghitung nilai error atau Root Mean Square Error (RMSE) dari tingkat layanan jalan atau Level of Service (LOS) dengan menggunakan tools Rapid Miner, metode/algoritma yang digunakan yaitu neural network. Data yang digunakan berjumlah 70 record dibagi menjadi 50 untuk data training dan 20 untuk data testing. Diharapkan dalam penelitian ini algortima yang digunakan bekerja dengan baik dengan tingkat error yang rendah sehingga bisa meningkatkan akurasi.

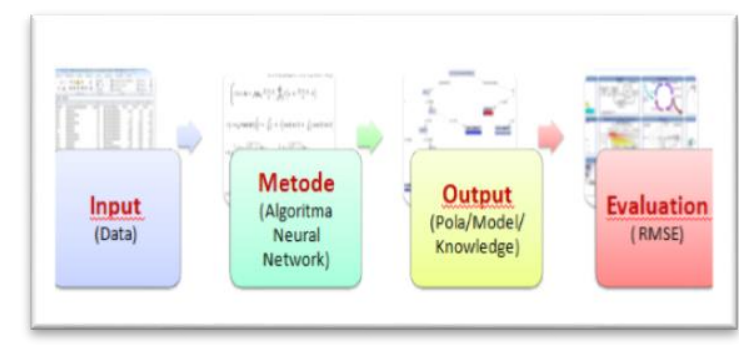

Gambar 3. Tahapan Proses Data Mining 


\section{Hasil dan Pembahasan}

Pada tahapan penelitian ini diawali dengan observasi awal dan pengumpulan data yang dilakukan pada tanggal 09 September 2016 di Dinas Perhubungan, Komunikasi dan Informasi Kabupaten Jepara . Dari hasil penelitian diperoleh data volume lalu lintas kabupaten Jepara pada tahun 2014 dan 2015. Berikut dokumentasi untuk observasi awal dan pengumpulan data.

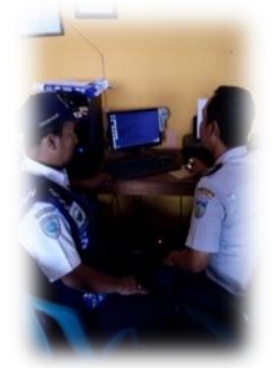

Gambar 4.1 Kegiatan Observasi awal dan pengumpulan data.

Penelitian ini merupakan penelitian tentang prediksi data arus lalu lintas jangka pendek dengan menggunakan data yang diperoleh dari Dinas Perhubungan, Komunikasi dan Informasi Kabupaten Jepara pada tahun 2014 dan 2015. Data yang diperoleh kemudian diinputkan dikomputer karena data yang diperoleh berupa hardcopy. Setelah data sudah siap kemudian data di diolah dengan menggunakan toolsrapidminer. Parameter yang digunakan antara lain: Nama (ID), Waktu, Motor Cycle (MC), Light Vehicle(LV), Heavy Vehicle (HV), Kapasitas (C), Volume (V), V/C dan kesimpulan label.

Pada eksperimen yang pertama dengan metode neural network dengan 70 record dibagi menjadi 50 untuk data training dan 20 untuk data testing sebagai berikut:

\begin{tabular}{|l|l|}
\hline \multicolumn{1}{|c|}{ Keterangan } & \multicolumn{1}{c|}{ Nilai } \\
\hline $\begin{array}{l}\text { Root Mean Squared Error } \\
\text { (RMSE) }\end{array}$ & 1.09 \\
\hline squared_error & $1.192+/-0.748$ \\
\hline
\end{tabular}

Tabel 4.1 Hasil Prediksi Arus Lalu Lintas

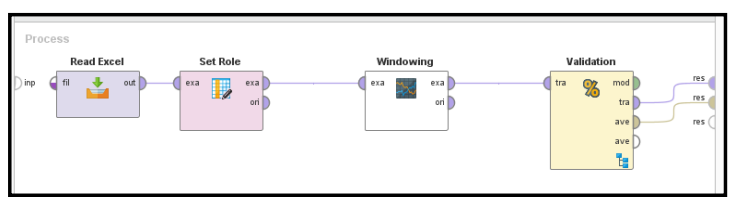

Gambar 4.2 Proses pengolahan data dengan tools Rapid Miner

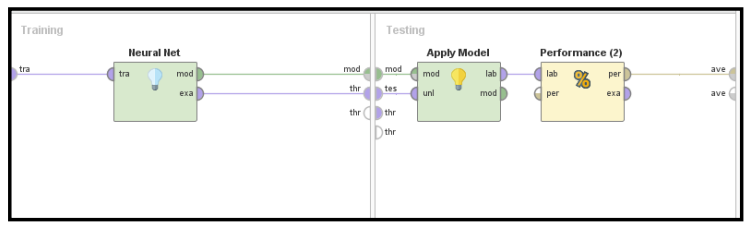

Gambar 4.3 Penerapan metode neural network dengan tools Rapid Miner

\section{root_mean_squared_error}

root mean squared error: $1.092+/-0.000$

\section{Gambar 4.4 Hasil Root Mean Squared Error}

\section{Pembahasan}

Dari penelitian yang terdahulu, Vedat Topuz (2010) Mengatakan bahwa algoritma prediksi data arus lalu lintas yang baik adalan Neural Network, dan Loreno (2014) yang melakukan penelitian dengan membandingkan beberapa algoritma data mining dan dihasilkan Neural Network yang lebih baik. Berdasarkan dari penelitian tersebut, penelitian ini dilakukan untuk membuktikan algoritma Neural Network akurat dalam prediksi data arus lalu laluu lintas. Dari hasil eksperimen dihasilkan nilai RMSE 1,092. 


\section{Kesimpulan}

Banyak penelitian tentang data arus lalu lintas dan menurut Ghadati (2013) dan Loreno (2014) mengatakanneural network yang paling akurat dalam prediksi data arus lalu lintas. Oleh sebab itu, penelitian ini dilakukan untuk membuktikan algoritma neural network yang paling akurat dalam prediksi data arus lalu lintas dengan menggunakan data volume lalu lintas kabupaten Jepara. Dari pengumpulan data diperoleh dataset sejumlah 70 record dengan pembagian 50 sebagai data training dan 20 sebagai data testing. Parameter yang digunakan antara lain : Nama (ID), Waktu, Motor Cycle (MC), Light Vehicle(LV), Heavy Vehicle (HV), Kapasitas (C), Volume (V), V/C dan kesimpulan label. Hasil penelitian yang diperoleh nilai root mean squared error sebesar 1,092. Hal ini membuktikan bahwa semakin rendah tingkat RMSEnya hasilnya semakin bagus.

\section{Daftar Pustaka}

Badan Pusat Statistik. 2016. Penduduk Indonesia Menurut Provinsi diunduh pada tanggal 8 September $2016 \mathrm{di}$ www.bps.go.id/linkTabelStatis/view/i $\mathrm{d} / 1267$

Ghadati Suciana.2013.Prediksi data arus lalu lintas jangka pendek menggunakan optimasi neural network berbasis genetik algorithm. Jurnal Teknologi Informasi, Volume 9 Nomor 2, Oktober 2013, ISSN 1414-9999

Lareno Bambang.2014.Analisa dan Perbandingan akurasi model prediksi rentet waktu arus lalu lintas jangka pendek. CSRID Journal,vol.6 no. 3 Oktober 2014 Hal. 148-158

Santoso Budi. 2007. Data Mining terapan dengan MATLAB. Yogyakarta, Indonesia: Graha IImu

Daniel T. Larose, Disccovering Konwledge in Data: An Introduction in Data Mining. Hoboken New Jersey, United States of America: John Willey \& Sons, Inc, 2005.

Raharjo Dwi Joko S.2013. Model artificial neural network Berbasis particle swarm optimization untuk
Prediksi laju inflasi. Jurnal Sistem Komputer - Vol.3, No.1, Juni 2013, ISSN: 2087-4685, e-ISSN: 22523456

Dishubkominfo Kab. Jepara. 2015. Studi Volume Lalu Lintas Kabupaten Jepara. Jepara: Dishubkominfo Kab. Jepara 